\title{
Raman spectroscopy combined with small angle X-ray scattering and wide angle $x$-ray scattering as a tool for the study of phase transitions in polymers
}

\author{
Citation for published version (APA): \\ Bryant, G. K., Gleeson, H. F., Ryan, A. J., Fairclough, J. P. A., Bogg, D., Goossens, J. G. P., \& Bras, W. (1998). \\ Raman spectroscopy combined with small angle $X$-ray scattering and wide angle $\mathrm{X}$-ray scattering as a tool for \\ the study of phase transitions in polymers. Review of Scientific Instruments, 69(5), 2114-2117. \\ https://doi.org/10.1063/1.1148907
}

DOI:

10.1063/1.1148907

Document status and date:

Published: 01/01/1998

\section{Document Version:}

Publisher's PDF, also known as Version of Record (includes final page, issue and volume numbers)

\section{Please check the document version of this publication:}

- A submitted manuscript is the version of the article upon submission and before peer-review. There can be important differences between the submitted version and the official published version of record. People interested in the research are advised to contact the author for the final version of the publication, or visit the DOI to the publisher's website.

- The final author version and the galley proof are versions of the publication after peer review.

- The final published version features the final layout of the paper including the volume, issue and page numbers.

Link to publication

\footnotetext{
General rights

- You may freely distribute the URL identifying the publication in the public portal. follow below link for the End User Agreement:

www.tue.nl/taverne

\section{Take down policy}

If you believe that this document breaches copyright please contact us at:

openaccess@tue.nl

providing details and we will investigate your claim.
}

Copyright and moral rights for the publications made accessible in the public portal are retained by the authors and/or other copyright owners and it is a condition of accessing publications that users recognise and abide by the legal requirements associated with these rights.

- Users may download and print one copy of any publication from the public portal for the purpose of private study or research.

- You may not further distribute the material or use it for any profit-making activity or commercial gain

If the publication is distributed under the terms of Article $25 \mathrm{fa}$ of the Dutch Copyright Act, indicated by the "Taverne" license above, please 


\title{
Raman spectroscopy combined with small angle x-ray scattering and wide angle x-ray scattering as a tool for the study of phase transitions in polymers
}

\author{
G. K. Bryant and H. F. Gleeson \\ Department of Physics and Astronomy, The University of Manchester, M13 9PL, United Kingdom
}

A. J. Ryan ${ }^{\text {a) }}$ and J. P. A. Fairclough

Manchester Materials Science Centre, UMIST, Grosvenor Street, Manchester M1 7HS, United Kingdom

D. Bogg

CCLRC Daresbury Laboratory, Warrington WA4 4AD, United Kingdom

J. G. P. Goossens

Centre for Polymers and Composites, Eindhoven Polymer Laboratories Technical University Eindhoven, P.O. Box 513, 5600 MB Eindhoven, Netherlands

W. Bras ${ }^{\text {b) }}$

DUBBLE CRG/ESRF, Netherlands Organisation for Scientific Research (NWO), clo ESRF BP220 F38042, Grenoble Cedex, France

(Received 16 May 1997; accepted for publication 30 January 1998)

\begin{abstract}
A novel combination of simultaneous experimental techniques has been developed as a tool for the study of phase transitions in polymers. Based upon a small angle x-ray scattering (SAXS) synchrotron radiation beamline it has been shown to be feasible to collect, in addition to the time-resolved SAXS data, wide angle x-ray scattering and Raman spectroscopy data with a time resolution of a few seconds. (C) 1998 American Institute of Physics. [S0034-6748(98)00105-1]
\end{abstract}

\section{INTRODUCTION}

The study of structural development by means of time resolved small angle x-ray scattering (SAXS) and/or wide angle $\mathrm{x}$-ray scattering (WAXS) has become a routine procedure at many synchrotron radiation (SR) laboratories. This has been enabled by the high intensity and good collimation of modern SR beamlines combined with relatively efficient electronics. The combination of techniques that can be performed simultaneously on a single sample offers a great opportunity to unequivocally obtain an accurate time correlation between the parameters derived from the different experiments. The combination of $\mathrm{x}$-ray based techniques like SAXS and WAXS is a logical step which has been implemented in several laboratories. ${ }^{1-3}$ However, in recent years the tendency to combine SR x-ray scattering with further complementary techniques has gained widespread popularity. The possibility to not only obtain structural information but also elucidate the thermodynamic behavior, by means of thermal analysis, ${ }^{4,5}$ has been shown to be particularly fruitful. Also the combination with light scattering, to elucidate large scale structures not accessible with $\mathrm{x}$-rays in a timeresolved mode, ${ }^{1}$ and Fourier transform infrared spectroscopy (FTIR) to monitor the chemical state of samples undergoing a chemical reaction, has been implemented. ${ }^{6}$

Being able to implement the combination of SAXS, WAXS, and FTIR the logical next step in instrumentation is

\footnotetext{
${ }^{a}$ Also at CCLRC Daresbury Laboratory, Warrington WA4 4AD, United Kingdom.

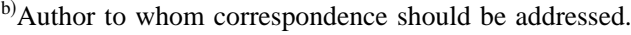

deemed to be the combination of x-ray scattering with Raman spectroscopy. This technique can provide complementary information to FTIR and in some cases even unique information. While FTIR is particularly useful in the study of polymers with polar groups in the side chain, Raman spectroscopy is a valuable tool to study the nonpolar groups and particularly the vibrations in the carbon chain of polymers. Experimentally, Raman spectroscopy also has some advantages. Fibre optics can be used for remote sampling and there are less restrictive conditions on light transmission. ${ }^{7}$

To justify implementing complicated technique combinations on a single sample it is obvious that it should be advantageous with respect to performing these techniques independently on identical samples. Considerations here can be a limited availability of the sample (often the case in biological applications) and sensitivity to sample damage induced by one of the techniques (e.g., x-rays) or the desire to carry out these experiments with such a high time framing rate that the comparison between the different experimental results becomes difficult due to instrumental uncertainties such as temperature in a rapid temperature jump experiment.

Initial experiments to investigate the feasibility of these experiments were performed with a home built spectrometer. ${ }^{8}$ It was shown that the experiments were feasible but the time resolution that could be achieved was too low to gain any advantages over performing these experiments independently. The replacement of this spectrometer with a new fast Raman spectrometer equipped with a fiber optic head has made it possible to increase the time resolution to approximately a frame every $2 \mathrm{~s}$. 


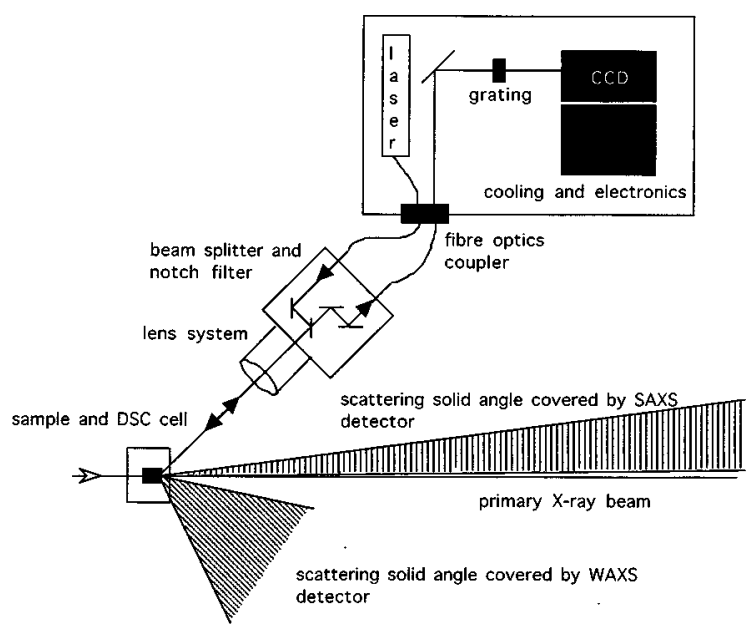

FIG. 1. Schematic description of the combined SAXS/WAXS/Raman experiment. For clarity the figure is not to scale and vacuum chambers and detectors have not been drawn. The SAXS detector is a standard Daresbury quadrant detector and the WAXS detector is a curved INEL detector with an opening angle which is electronically set to be $60^{\circ}$. The distance between the SAXS detector and the sample is variable and can be adjusted to the required $q$ range that one wants to study.

\section{EXPERIMENT}

Experiments were carried out at the SAXS/WAXS station 8.2 at the SRS Daresbury Laboratory (UK). This beamline has been described extensively elsewhere ${ }^{2}$ and we will only give a brief description here. Bending magnet radiation (5 mrad) from the SR source is focused by a cylindrical bent triangular Ge (111) crystal with an $11.5^{\circ}$ Fankuchen cut, positioned so that a wavelength of $1.5 \AA$ is selected, and a 70 $\mathrm{cm}$ long fused quartz mirror, into a spot of $3.0 \times 0.3 \mathrm{~mm}^{2}$ $(H \times V)$. A 3:1 demagnification of the source is achieved. The focal spot is placed on the optical bench between the SAXS and WAXS detectors (see Fig. 1). The WAXS pattern is collected with a curved INEL detector ${ }^{9}$ electronically set up to detect $60^{\circ}$, the SAXS pattern with a standard Daresbury quadrant detector. Scattering vectors $(q=2 \pi / d)$ between $0.007<q<2.5 \AA^{-1}$ can be observed. The dataacquisition electronics for the two detectors is driven by software enabling time-slicing and the generation of transistor-transistor logic (TTL) pulses which act as the timing signal for the electronics associated with the additional experiments ${ }^{10}$ thus enabling accurate time correlations to be made.

A Kaiser Holoprobe 532 Raman spectrometer with a fiber optic probe consisting of a fibre for the laser light and one for the scattered radiation, to allow remote sampling was used to obtain the Raman spectrum. It utilizes a diode pumped frequency doubled $\mathrm{Nd}$ yttrium aluminum garnet laser with an excitation wavelength of $5320 \AA$. A holographic filter in the probe head is used to reject the unshifted laser light. The light is focused on the spectrograph using an aberration corrected lens with aperture $f / 1.8$. The detector is a thermoelectrically cooled charge coupled device. To focus the light on the sample a microscope objective with $10 \times$ magnification was used. Instead of a moving mirror system a holographic grating is used as the dispersive element thus enabling data to be obtained with a high time resolution. This spectrometer can collect data over a range from $50-4000 \mathrm{~cm}^{-1}$. Figure 1 shows a schematic diagram of the experimental equipment. For clarity the components have not been drawn to scale and the vacuum chamber used for the $\mathrm{x}$-ray experiment is not shown. This vacuum chamber covers most of the $\mathrm{x}$-ray path and is needed to avoid parasitic scatter and absorption of the x-rays. The sample is not held in vacuum but in a Linkam scientific differential scanning calorimeter (DSC) stage which allows free access to both the $\mathrm{x}$-rays and the laser light. The distance from the sample to the (curved) WAXS detector is fixed but the sample-SAXS detector distance can be varied between $0.5-4 \mathrm{~m}$.

\section{RESULTS}

It proved not to be possible to set up the Raman spectrometer in a master-slave combination with the SAXS/ WAXS electronic system since this would require an adaptation of the spectrometer software. This is no intrinsic limitation but for the test experiments described here the decision was made to start the spectrometer scan manually each time the station computer signaled the start of a new time frame. X-ray scattering data was collected in time frames of 1 min length. The estimated maximum error in the time correlation between the scattering and Raman experiment was on the order of $2 \%$.

To investigate the performance of the system a sample of high density polyethylene was used. This material has been investigated extensively with both time resolved SAXS/ WAXS and Raman spectroscopy. ${ }^{11-13}$ In Fig. 2 the results of a heating experiment on this material are shown. The data is represented as three-dimensional plots of the SAXS, WAXS, and Raman curves. The sample was heated with a fixed heating rate of $5^{\circ} \mathrm{C} / \mathrm{min}$ from $80^{\circ} \mathrm{C}$ to $180^{\circ} \mathrm{C}$. The diagonal axis in all three plots is the time/temperature axis. On the vertical axis in the SAXS data the value of $I(q) q^{2}$ is used. This is the commonly used Lorentz correction for lamellar systems. Both the Raman data as well as the WAXS data have an arbitrary $z$-axis scale. In Fig. 3 a combination of the results of all three techniques is shown. The value of the relative invariant, $Q=\int_{0}^{\infty} I(q) q^{2} d q$, is given. The invariant is dominated by the intensity in the SAXS region of the x-ray spectrum. Extrapolations to $q \rightarrow 0$ and $q \rightarrow \infty$ have been used to obtain the total values. The invariant is an important parameter which is a measure for structure formation. From the WAXS data a measure of the degree of crystallinity can be obtained by using the assumption that the integrated area under the crystalline peaks has a linear correlation with the degree of crystallinity. In this graph an integration over the 110 peak in the WAXS pattern is used. It is noteworthy that a two phase system an internal scale for the crystallinity can be constructed by using the maximum of the invariant as the point of 50\% crystallinity (in volume). See for this Ref. 11. The integrated value of a peak in the Raman spectrum $\left(1246-1338 \mathrm{~cm}^{-1}\right)$ is coplotted. This peak is very strong in the spectrum of solid polyethylene but in liquid polyethylene only a broad weak peak can be found (maximum $1303 \mathrm{~cm}^{-1}$ ) and is associated with the $\mathrm{CH}_{2}$ vibration (gauche-transgauche conformation) in the amorphous phase of polyethylene. It should be remarked that any peak in the Raman data 

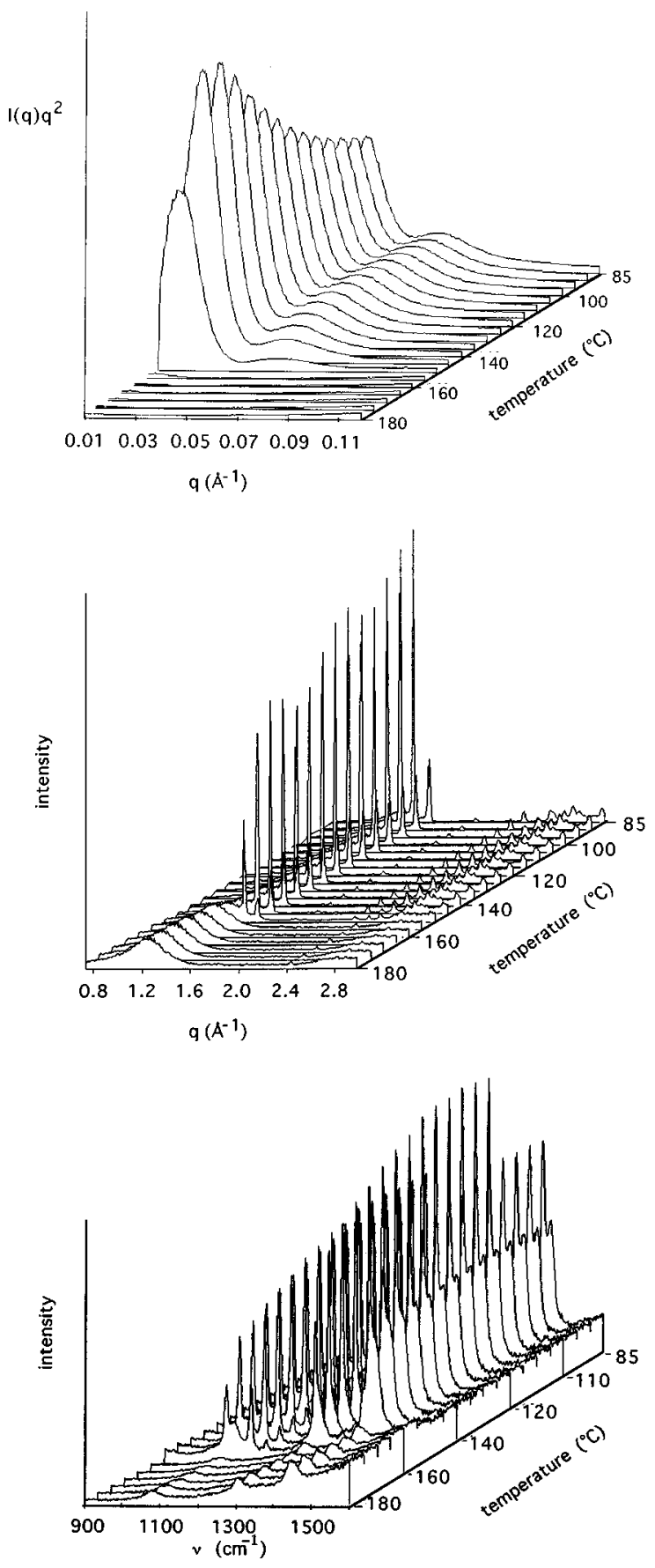

FIG. 2. Three-dimensional plots from a simultaneous (a) SAXS, (b) WAXS, (c) Raman spectroscopy experiment performed on a sample of polyethylene which was heated at a constant rate from 80 to $180^{\circ} \mathrm{C}$. The time/ temperature axis is plotted diagonally in reversed direction for clarity. The scattering experiments are corrected for beam decay and absorption. All intensities are on a relative scale.

could have been chosen depending on which chemical bond one wants to study in association with the structural parameters obtained from the $\mathrm{x}$-ray scattering techniques. The slow decline in the intensity of the 110 reflection before the invariant reaches its maximum indicates that the sample were more than $50 \%$ crystalline from the onset. The decay of the $1303 \mathrm{~cm}^{-1}$ peak in the Raman spectrum is slower than the decay in the intensity of the 110 reflection in the WAXS spectrum, thus suggesting that the crystalline phase melts earlier than the amorphous phase.

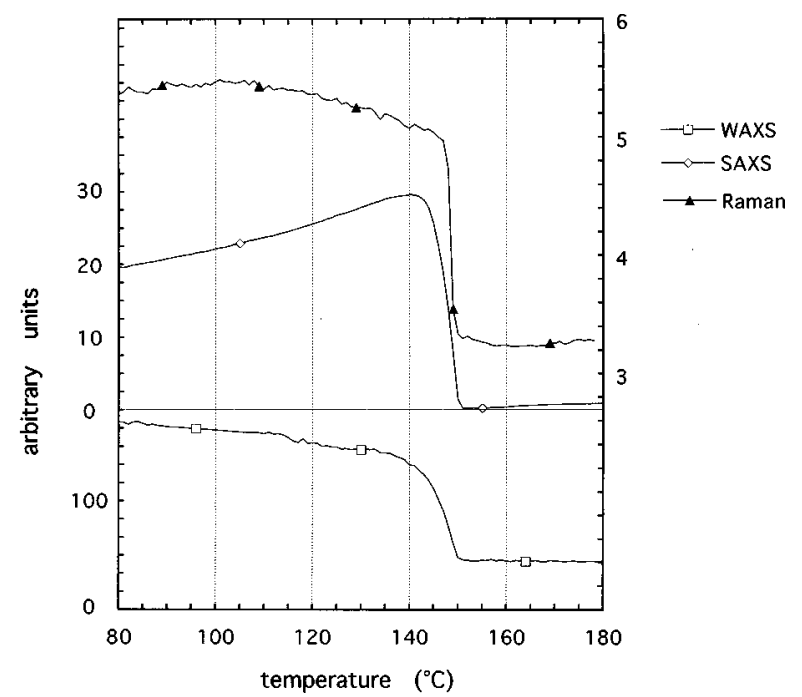

FIG. 3. Data derived from the plots shown in Fig. 2. WAXS indicates the integrated intensity of the 110 peak in the WAXS pattern which is linearly related to the degree of crystallinity. SAXS indicates the relative invariant $Q=\int_{0}^{\infty} I(q) q^{2} d q$ which is dominated by the scattered intensity in the SAXS region and further determined by extrapolations for $q \rightarrow 0$ and $q \rightarrow \infty$. Raman indicates the integrated value of the peak in the region $\left(1246-1338 \mathrm{~cm}^{-1}\right)$. The $z$ axes in this combined figure are in arbitrary units. For a further explanation see the text.

Another example of the usefulness of this technique is shown in Fig. 4. This concerns an experiment to elucidate some aspects of the (technologically important) processing of polymers using reactive solvents (monomers) which are polymerised in situ. ${ }^{14}$ Upon polymerization liquid-liquid (L-L) and liquid-solid (L-S) phase separations can occur. In this example the behavior of polyethylene in styrene is shown. The experiment is performed at a constant temperature of $120^{\circ} \mathrm{C}$. In the SAXS data evidence of the L-L phase separation can be observed by the development of a peak that occurs at $q \approx 0.01 \AA^{-1}$ and which moves slowly towards lower $q$ values. The second peak that occurs is due to the $\mathrm{L}-\mathrm{S}$ phase transition. Both the $\mathrm{L}-\mathrm{L}$ and $\mathrm{L}-\mathrm{S}$ phase separation are accompanied by a strong change in optical density of the system. The reaction kinetics can be monitored by the decrease of the intensity of the peak at $1630 \mathrm{~cm}^{-1}$ which is part of the styrene spectrum and is related to the $\mathrm{C}=\mathrm{C}$ bond and which opens up upon polymerization. For quantitative analysis a reference peak is needed for normalization. This can be found at $621 \mathrm{~cm}^{-1}$. The advantage of Raman spectroscopy over FTIR for this type of system now becomes clear. With FTIR the experiment would be impossible since it is sensitive to the optical density of the system and possible changes in peak height would be convoluted with changes in transparency of the sample.

The $\mathrm{L}-\mathrm{S}$ solid phase transition (at $\approx 30 \mathrm{~min}$ after the onset of the experiment) can be observed in both the WAXS data, where peaks due to crystalline polyethylene occur, as well as in the Raman spectra where, in the spectral region of $1050-1150 \mathrm{~cm}^{-1}$, two peaks appear originating from crystalline polyethylene appear together with a change in the intensity of the total spectrum.

Systematic errors can be introduced due to the fact that the x-ray scattering arises from the bulk of the sample while 

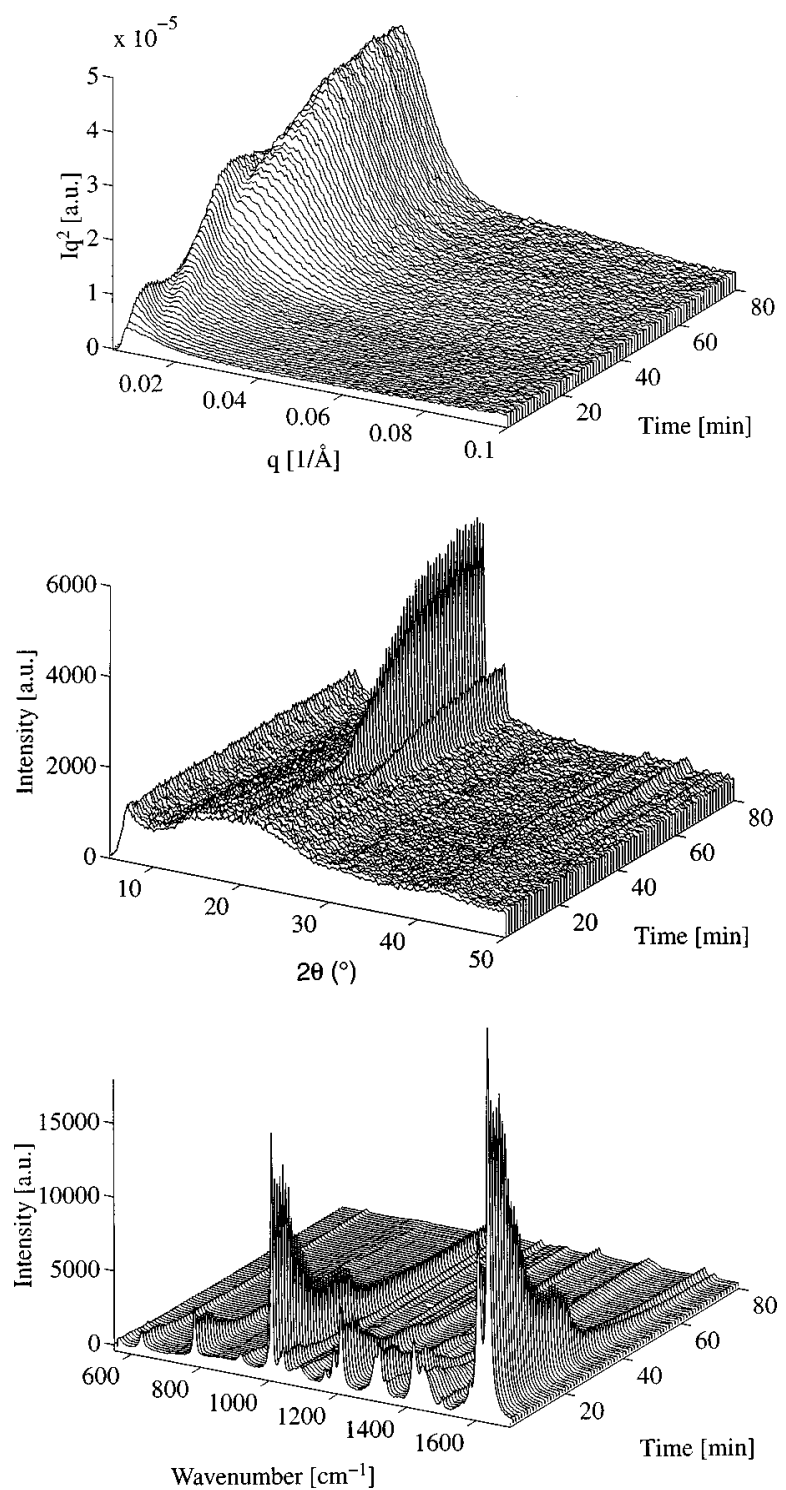

FIG. 4. Three-dimensional plots of the isothermal $\left(120^{\circ} \mathrm{C}\right)$ polymerization of polyethylene in styrene. The meaning of the effects seen in these plots is discussed in the text. (a) SAXS, (b) WAXS, (c) Raman.

the Raman scattering probes the surface. However the use of the fiber optic head with the $10 \times$ magnification lens also allowed optical access to the sample position even when using an online Linkam DSC. This instrument is designed to minimize thermal gradients in the sample. ${ }^{4}$ By using this device it is possible to avoid the introduction of discrepancies due to thermal gradients. The possibility to obtain thermodynamic information from the DSC signal is an extra bonus.

\section{DISCUSSION}

The simultaneous combination of SAXS, WAXS, and Raman spectroscopy has successfully been implemented. This combination of techniques have shown to be an extremely useful tool in the study of phase transitions in online polymer processing. This is a welcome addition to the previously developed combination of $\mathrm{x}$-ray scattering and FTIR. The remote sampling of the Raman scattering by using a fiber optics mounted optical probe offers a large potential for the further application of this technique. The application of $\mathrm{x}$-ray fiber diffraction techniques, combined with Raman spectroscopy, applied to polymers which are mechanically deformed, by for instance stretching or shear flow, is only one of the numerous examples. Although for all test experiments polymeric systems have been used this does not necessarily mean that the application is limited to such systems.

\section{ACKNOWLEDGMENTS}

The staff at Daresbury Laboratory has been extremely helpful, particularly the safety group, Ernie Komanschek, Dave Bouch, and Paul Hindley whose technical support was essential for the success of this work. The Kaiser Holoprobe was kindly loaned by Dr. John Andrews of Clairet Scientific.

\footnotetext{
${ }^{1}$ M. Bark and H. G. Zachmann, Acta Polym. 44, 259 (1993).

${ }^{2}$ W. Bras, G. E. Derbyshire, A. J. Ryan, G. R. Mant, A. Felton, R. Lewis, C. Hall, and N. Greaves, Nucl. Instrum. Methods Phys. Res. A 326, 587 (1993).

${ }^{3}$ B. S. Hsiao, K. C. H. Gardner, D. Q. Wu, and B. Chu, Polymer 34, 3986 (1993).

${ }^{4}$ W. Bras, G. E. Derbyshire, A. J. Ryan, J. Cooke, A. Devine, B. E. Komanschek, and S. M. Clark, J. Appl. Crystallogr. 28, 26 (1995).

${ }^{5}$ T. P. Russell and J. T. Koberstein, J. Polymer Sci. 23, 1109 (1985).

${ }^{6}$ W. Bras, G. E. Derbyshire, D. Bogg, J. Cooke, M. J. E. Elwell, S. N. Naylor, B. E. Komanschek, and A. J. Ryan, Science 267, 996 (1995).

${ }^{7}$ J. L. Koenig, Spectroscopy of Polymers (American Chemical Society, Washington, DC, 1992).

${ }^{8}$ W. Bras and A. J. Ryan, J. Mol. Struct. 383, 309 (1996).

${ }^{9}$ J. Ballon, V. Comparat, and J. Pouxe, Nucl. Instrum. Methods 217, 213 (1983).

${ }^{10}$ G. R. Mant (private communication).

${ }^{11}$ A. J. Ryan, W. Bras, G. R. Mant, and G. E. Derbyshire, Polymer 35, 4537 (1994).

${ }^{12}$ N. Stribeck, R. G. Alamo, L. Mandelkern, and H. G. Zachman, Macromolecules 28, 5029 (1995).

${ }^{13}$ K. Tashiro, M. Satkowski, R. Stein, Y. Li, B. Chu, and S. Hsu, Macromolecules 25, 1809 (1992).

${ }^{14}$ J. G. P. Goossens, S. Rastogi, H. E. H. Meijer, and P. J. Lemstra (unpublished).
} 